\title{
Detection of protein glycation inhibitory potential of nine antidiabetic plants using a novel method
}

\author{
H.K.I. Perera', C.S. Handuwalage $\mathrm{e}^{1,2}$ \\ ${ }^{1}$ Department of Biochemistry, Faculty of Medicine, University of Peradeniya, Sri Lanka, ${ }^{2}$ Postgraduate Institute of Science, \\ University of Peradeniya, Sri Lanka
}

Background: Protein glycation is a major cause of chronic diabetic complications. Medicinal plants with protein glycation inhibitory potential will be beneficial to prevent or delay diabetic complications. Objective: The objective of the study was to analyze protein glycation inhibitory potential of ten plants among which nine are well known for their antidiabetic effects. Methods: Methanol extracts were prepared using parts from nine plants namely, Coccinia grandis, Ficus racemosa, Gymnema lactiferum, Gymnema sylvestre, Musa paradisiaca, Phyllanthus debilis, Phyllanthus emblica, Strychnos potatorum and Tinospora cordifolia. Dried latex of Pterocarpus marsupium was used without further extraction. Glycation inhibitory potential of the extracts was analyzed using bovine serum albumin (BSA) and fructose, incubated in the presence or absence of plant extracts for 4 week. Appropriate controls and blanks and the standard inhibitor aminoguanidine were included. A novel native polyacrylamide gel electrophoresis (PAGE) method established recently was used to detect the effect of plant extracts on the BSA glycation. Results: Previously we have demonstrated that the BSA migration towards the anode is increased proportionate to the degree of glycation. This increase was comparatively less when the glycation was inhibited. Accordingly, most promising antiglycation effects were observed with $P$. debilis (whole plant), $P$. emblica (fruit) and $P$. marsupium (latex). $F$. racemosa (stem bark) showed the highest inhibition among the remaining extracts. G. sylvestre (leaf), M. paradisiaca (yam) and T. cordifolia (leaf) also showed promising inhibition. C. grandis (leaf) and S. potatorum (seed) showed lower inhibition. Lowest inhibition was observed with $G$. lactiferum (leaf). Conclusion: We have demonstrated the antiglycation potential of some antidiabetic plants, using a novel method developed by us recently. Extracts of $P$. debilis, $P$. emblica and $P$. marsupium showed a strong protein glycation inhibitory potential.

Key words: AGE, Glycation inhibition, PAGE, Antidiabetic plants

\section{INTRODUCTION}

Protein glycation is a non enzymatic process which leads to the formation of stable irreversible group of compounds known as advanced glycation end products (AGEs). Amount of AGEs formed on a protein depends on the reactivity of specific amino groups, reactivity of the sugar, sugar concentration and the half-life of the protein. ${ }^{1}$ Chronic hyperglycaemia associated with diabetes mellitus and the oxidative stress accelerates AGE production. AGEs are fluorescent and non fluorescent complex adducts which are accumulated predominantly on long-lived proteins such as collagen, compromising their physiological functions. ${ }^{1}$ Acceleration of AGE levels in the body is a major cause for micro and macro vascular complications such as retinopathy, nephropathy and atherosclerosis associated with diabetes mellitus. ${ }^{1-4}$ Several lines of evidence suggest the deleterious effects of AGEs leading to endothelial dysfunction and pathogenesis of vascular complications. ${ }^{4}$ 
Scientific literature identifies inhibition of AGE formation as one of the therapeutic approaches to prevent the progression of diabetic complications. Several synthetic compounds have been evaluated for their inhibitory effects against the formation of AGEs. However, many synthetic inhibitors were not successful at clinical trials due to safety issues. ${ }^{1}$ Numerous medicinal plants are being used to treat diabetes from ancient times with little or no side effects. ${ }^{5}$ However, majority of traditional antidiabetic plants await proper scientific evaluation for their ability to prevent the chronic diabetic complications. Plants with protein glycation inhibitory potential will be beneficial in this regard. ${ }^{1}$ Glycation inhibitors present in antidiabetic plants appear important candidates for the development of new therapeutics against diabetic complications which will also provide protection against hyperglycaemia and possibly the oxidative damage, as part of the overall diabetes management. However, adequate work has not yet been done in on this area especially in Sri Lanka. Analytical techniques available to identify protein glycation inhibitors require expensive specialized equipment $t^{6-8}$ which might be one of the limiting factor regarding glycation studies. The objective of the study was to analyze protein glycation inhibitory potential of ten plants among which nine are well known for their antidiabetic effects using a relatively simple novel method established by us recently.

\section{MATERIALS AND METHODS}

Parts from ten plants were collected namely, Coccinia grandis (L.) J. Voigt (Kowakka) leaves, Ficus racemosa L. (Attikka) stem bark, Gymnema lactiferum (L.) R. Br. ex Schult (Kurinnan) leaves, Gymnema sylvestre (Retz.) R. Br. ex Schult (Masbedda) leaves, Musa X paradisiaca L. (Alu kesel) yam, Phyllanthus debilis Klein ex Willd (Pitawakka) whole plant, Phyllanthus emblica L. (Nelli) fruit, Pterocarpus marsupium Roxb. (Gammalu) latex, Strychnos potatorum L. f. (Ingini) seeds and Tinospora cordifolia (Willd.) Hook.f. \& Thoms. (Rasakinda) leaves. Plants were authenticated and specimens were deposited at the National Herbarium, Royal Botanical Garden, Peradeniya. P. marsupium latex was dried under shade without further processing. Rest of the plant materials were cleaned, dried under shade and ground to a fine powder using a grinder. Dry powder $(10 \mathrm{~g})$ was extracted with methanol $(100 \mathrm{ml})$ using the ultrasonicator. Methanol extract was filtered and the solvent was evaporated by rotary evaporator (Buchi RII) at $45-50^{\circ} \mathrm{C}$. These crude extracts were stored at room temperature until further analysis.

Protein glycation was carried out using bovine serum albumin (BSA) and fructose $(0.5 \mathrm{M}) .^{7}$ Protein and sugar incubations were carried out in the presence of plant extracts [ $5 \mathrm{mg}, 0.5 \mathrm{mg} / \mathrm{ml}$ in phosphate buffer $(\mathrm{pH} 7.4)$ and other suitable concentrations depending on the inhibitory activity of the extract] at $37^{\circ} \mathrm{C}$ for 4 week. BSA and fructose mixture in absence of plant extract was used as the positive control. Corresponding test blanks were prepared in the absence of fructose. Standard inhibitor aminoguanidine (AG) $(10 \mathrm{mM})$ was included. Aliquots were collected at intervals for further analysis with polyacrylamide gel electrophoresis.

A novel native PAGE method established by us was used to detect the effect of plant extracts on the BSA glycation.? Polyacrylamide gels $(10 \%)$ were prepared according to the standard technique. Samples were loaded under native conditions. Electrophoresis was carried out using Enduro Vertical Gel Electrophoresis system- E2010-P according to the standard Laemmli method. ${ }^{10}$ After separation at $\mathrm{pH}$ 8.6, protein bands were visualized by staining with Coomassie brilliant blue. Changes in the migration position of BSA bands were compared. Approximate percentage inhibition of glycation was assessed based on the decrease in migration of BSA in the presence of plant extract, in comparison to the positive control.

\section{RESULTS}

Previously we have demonstrated that the increase in BSA migration towards the anode in presence of fructose (compared to the migration of test blank), is proportionate to the degree of glycation. ${ }^{9}$ According to the findings of the present study with different concentrations of plant extracts used $[5 \mathrm{mg} / \mathrm{ml}$ (Figure 1), $0.5 \mathrm{mg} / \mathrm{ml}$ (Figure 2A), $50 \mu \mathrm{g} / \mathrm{ml}$ (Figure 2B left) and $2 \mathrm{mg} / \mathrm{ml}$ (Figure 2B right)], most promising antiglycation effects with almost $100 \%$ inhibition were observed with P. debilis whole plant, P. emblica fruit (Figure 2B left panel) and P. marsupium latex (Figure 3). F. racemosa (stem bark) showed the highest inhibition among the remaining seven plant extracts (Figure $2 \mathrm{~A}$ right panel). Glycation inhibition with $P$. debilis, $P$. emblica, $P$. marsupium and F. racemosa extracts at $0.5 \mathrm{mg} / \mathrm{ml}$ were greater than that of AG (Figure 2A). G. sylvestre (leaf), M. paradisiaca (yam) and T. cordifolia (leaf) also showed nearly $100 \%$ inhibition at $2 \mathrm{mg} / \mathrm{ml}$ (Figure $2 \mathrm{~B}$ Right panel) However, G. sylvestre and M. paradisiaca did not show any inhibition at $0.5 \mathrm{mg} / \mathrm{ml}$ extract while T. cordifolia showed only a mild inhibition (Figure 2A). Lower inhibitions were observed with $C$. grandis (leaf) and $S$. potatorum (seed) (Figure 2 B Right panel and Table 1). Lowest inhibition found was with $G$. lactiferum (leaf) (Figure 1, 2B Right panel and Table 1). Summary of the results is shown in the table 1. 


\begin{tabular}{|c|c|c|c|c|}
\hline Plant part & $5 \mathrm{mg} / \mathrm{ml}$ & $2 \mathrm{mg} / \mathrm{ml}$ & $0.5 \mathrm{mg} / \mathrm{ml}$ & $50 \mu \mathrm{g} / \mathrm{ml}$ \\
\hline Coccinia grandis leaves & $>50 \%$ & $\sim 20 \%$ & 0 & \\
\hline Ficus racemosa bark & Some interference & & $\sim 50 \%$ & $\sim 20 \%$ \\
\hline Gymnema lactiferum leaves & $<50 \%$ & $<20 \%$ & 0 & \\
\hline Gymnema sylvestre leaves & $>50 \%$ & $\sim 80 \%$ & 0 & \\
\hline Musa paradisiaca yam & $>50 \%$ & $\sim 80 \%$ & 0 & \\
\hline Phyllanthus debilis plant & Interference & & $\sim 100 \%$ & $\sim 100 \%$ \\
\hline Phyllanthus emblica fruit & Interference & & $\sim 100 \%$ & $\sim 100 \%$ \\
\hline Pterocarpus marsupium latex & Interference & & $\sim 100 \%$ & $\sim 100 \%$ \\
\hline Strychnos potatorum seeds & $\sim 50 \%$ & $\sim 20 \%$ & 0 & \\
\hline Tinospara cordifolia leaf & Some interference & $\sim 80 \%$ & $\sim 20 \%$ & \\
\hline
\end{tabular}

Approximate percentage inhibitions are stated based on the differences in the degree of the BSA movement towards the anode, compared to that of uninhibited control. Concentrations of plant extracts used were at $5,2,0.5 \mathrm{mg} / \mathrm{ml}$ and $50 \mathrm{\mu g} / \mathrm{ml}$. Interference: BSA migration was affected at $5 \mathrm{mg} / \mathrm{ml}$ plant. Empty spaces indicate that the experiments were not conducted at the respective concentrations of the extracts

- Fructose CG

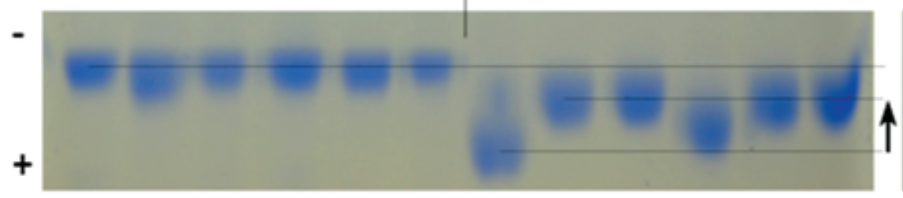

- Fructose

+ Fructose

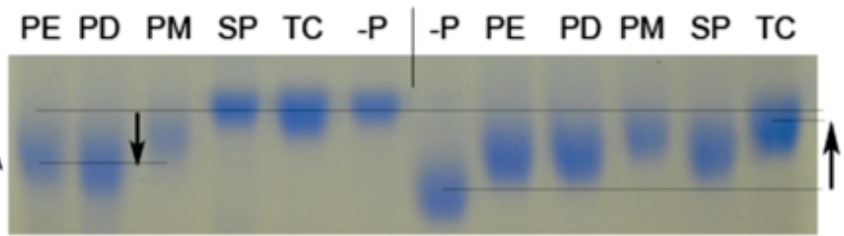

Figure 1: Effect of presence of plant extracts $(5 \mathrm{mg} / \mathrm{ml})$ on BSA migration. PAGE was conducted. -P: in absence of plant. Rest of the incubations was conducted in presence of following. AG: Aminoguanidine (10 mM), CG: C. grandis, FR: F. racemosa, GL: G. lactiferum, GS: G. sylvestre, MP: M. paradisiaca, PE: P. emblica, PD: P. debilis, PM: P. marsupium, SP: S. potatorum and TC: T. cordifolia. Plant concentration used was 5 $\mathrm{mg} / \mathrm{ml}$. Incubations were carried out in presence of fructose (+ Fructose) or in absence of fructose (- Fructose). Incubation period was 27 days. Arrow to the top shows the decrease in BSA migration in presence of plant extracts. Downward arrow shows the increase in BSA migration in presence of higher concentrations of PD, PE and PM extracts
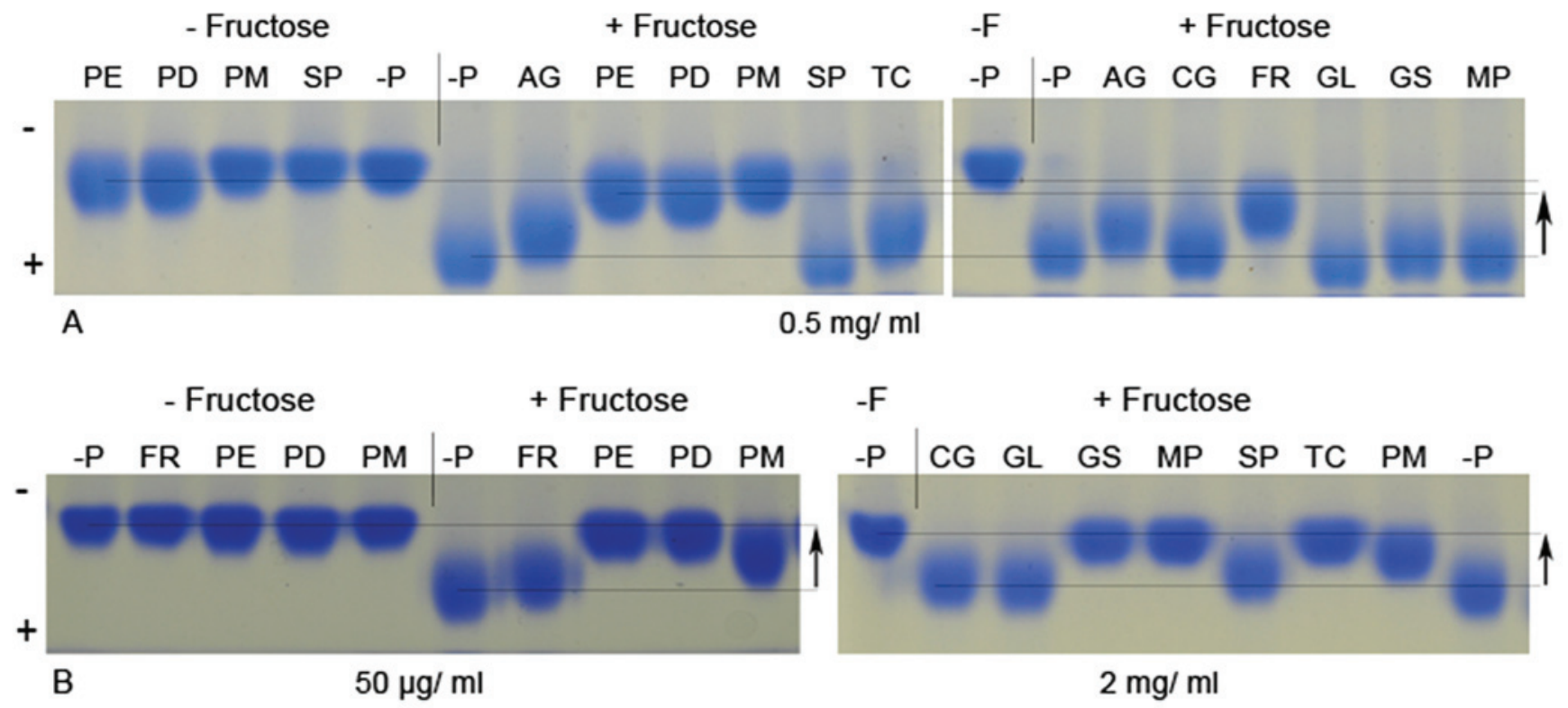

Figure 2: Effect of presence of plant extracts $(0.5 \mathrm{mg}, 50 \mu \mathrm{g}$ and $2 \mathrm{mg} / \mathrm{ml})$ on BSA migration. PAGE was conducted. -P: in absence of plant. Rest of the incubations was conducted in presence of following. AG: Aminoguanidine (10 mM), CG: C. grandis, FR: F. racemosa, GL: G. lactiferum, GS: G. sylvestre, MP: M. paradisiaca, PE: P. emblica, PD: P. debilis, PM: P. marsupium, SP: S. potatorum and TC: T. cordifolia. Incubations were carried out in presence of fructose (+ Fructose) or in absence of fructose (-F or - Fructose). Arrows show the decrease in BSA migration in presence of plant extracts. 2A: Plant concentration used was $0.5 \mathrm{mg} / \mathrm{ml}$ with all ten extracts. Incubation period was 15 days. $2 \mathrm{~B}$ : Plant concentration used was $50 \mu \mathrm{g} / \mathrm{ml}$ with FR, PD and PE (2B left panel), $<50 \mu \mathrm{g} / \mathrm{ml}$ with PM (2B left and right panels) and others with $2 \mathrm{mg} / \mathrm{ml}$ (2B Right panel). Incubation period was 7 days 


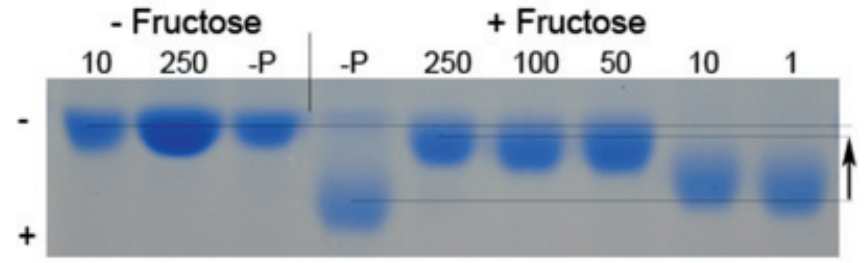

Figure 3: Effect of presence of $P$. marsupium on BSA migration. PAGE was conducted. -P: in absence of plant. Incubations were carried out in presence of fructose (+ Fructose) or in absence of fructose (- Fructose). Concentrations of the extract used were 1, 10, 50, 100 and $250 \mu \mathrm{g} / \mathrm{ml}$. Incubation period was 14 days. Arrow shows the decrease in BSA migration in presence of PM latex. Inhibition observed was nearly $100 \%$ with the extract at $50 \mu \mathrm{g} / \mathrm{ml}$ and above

At higher concentrations $(5 \mathrm{mg} / \mathrm{ml})$ P. debilis, P. emblica and $P$. marsupium showed an increase in the BSA movement even in absence of fructose (Figure 1-downward arrow). This interference was gradually lost, when the concentrations of these extracts were reduced to $0.5 \mathrm{mg}$ (Figure $2 \mathrm{~A}$ ) and $50 \mu \mathrm{g} / \mathrm{ml}$ (Figure 2B left panel).

\section{DISCUSSION}

All the plants tested in our study, other than G. lactiferum are being used to treat diabetes since ancient times ${ }^{5}$ and almost all are proven for their hypoglycaemic potential experimentally too. ${ }^{5,11,13}$ The PAGE method used to detect the inhibition of glycation was a novel method developed by us recently which can be conducted without expensive equipment. Previously we have demonstrated that the increase in BSA migration towards the anode in comparison to that of test blank was proportionate to the degree of glycation. ${ }^{9}$ This increase was comparatively less in a dose-dependent manner, when the glycation was inhibited. ${ }^{9}$ With the present study, we were able to demonstrate the antiglycation potential of the plants tested, identifying an additional beneficial effect which will prevent or delay chronic diabetic complications.

Among the tested, $P$. debilis whole plant, $P$. emblica fruit and $P$. marsupium latex showed a very strong antiglycation potential. They showed almost $100 \%$ inhibition even at $50 \mu \mathrm{g} / \mathrm{ml}$ plant. At higher concentrations ( $5 \mathrm{mg} / \mathrm{ml}$ ) those three extract showed an increase in the BSA movement independent of fructose, masking their inhibitory effects on glycation. This interference was not there when lower concentrations of extracts $(50 \mu \mathrm{g} / \mathrm{ml})$ were used. Highest inhibitory effects among the remaining seven extracts were seen in F. racemosa. These extracts seem to contain phytochemicals which add negative charges to BSA when used at higher concentrations.

There are some studies reporting the antiglycating activity of three plants parts, C. grandis leaf, G. lactiferum leaf and
P. emblica fruit, included in our study. A few studies have shown antiglycating effects of different parts obtained from $M$. paradisiaca (inflorescence), T. cordifolia (stem) and P. marsupium (bark) mostly using animal models. We could not find any previous reports on the antiglycating effects of F. racemosa, G. sylvestre, $P$. debilis and $S$. potatorum plant parts. We found evidence for particularly high antiglycating effects in $P$. debilis and $F$. racemosa in this study.

C. grandis leaves and P. emblica fruit were tested previously for their antiglycating activity in vitro using the BSA model and quantified the glycation products based on the fluorescent intensity revealing a strong antiglycation potential in $P$. emblica fruit. ${ }^{7,14}$ Perera et al., revealed that the water extracts of $P$. emblica fruit show significant antiglycation activity with an $\mathrm{IC}_{50}$ of around $75 \mu \mathrm{g} / \mathrm{ml} .^{14}$ They used BSA and $500 \mathrm{mM}$ glucose incubated under different conditions (at $60^{\circ} \mathrm{C}$ for $24 \mathrm{~h}$ ) and quantified relative amounts of glycated BSA, based on the fluorescent intensity using a fluorescent microplate reader. In addition, $P$. emblica was also effective in delaying the progression of diabetic cataract in streptozotocin induced diabetic rats. ${ }^{15}$ Our results on $P$. emblica with the novel method support the findings of previous studies carried out in vitro and in vivo, showing a strong antiglycating effect. Ethanol extracts of C. grandis leaves $(0.5 \mathrm{mg})$ on the inhibition of the middle stage of protein glycation was tested by incubating BSA and methylglyoxal or glucose for 3 days with/without the extract followed by the measurement of fluorescence intensity. ${ }^{16}$ Their results indicated a comparatively higher glycation inhibition $(96 \%)$ in presence of ethanol extracts of $C$. grandis leaf. We observed a good inhibition with methanol extracts of C. grandis at $5 \mathrm{mg} / \mathrm{ml}$, but not at $0.5 \mathrm{mg} / \mathrm{ml}$. Our findings with another very sensitive assay conducted on glycation induced protein cross-linking tallied with the results of the present study (unpublished data). G. lactiferum leaf was tested for antiglycating effects using type 2 diabetic patients. A significant reduction in the $\mathrm{HbA}_{1 \mathrm{C}}$ levels was observed when a suspension of $G$. lactiferum leaf powder was given twice daily for four weeks. ${ }^{17}$ However, in our study, the lowest glycation inhibitory effects were shown by G. lactiferum. A comparison cannot be made between the two studies as even a hypoglycaemic effect itself can show an effect on reducing glycation in vivo.

M. paradisiaca (inflorescence) has showed effective antiglycation potential as demonstrated by a spectrofluorimeter. ${ }^{18}$ In our study methanolic extract of $M$. paradisiaca yam showed a good antiglycation potential. Antiglycating activity of T. cordifolia stem-derived alkaloids was evaluated against lens aldose reductase isolated from male Wistar rats. ${ }^{19}$ Another study demonstrated the inhibitory activity of T. cordifolia stem bark against lens 
aldose reductase isolated from normal Wistar rats with an $\mathrm{IC}_{50}$ of $103 \mu \mathrm{g} / \mathrm{ml}$. They also showed preventive effects of T. cordifolia stem bark against diabetic neuropathy in female Wistar rats. ${ }^{20}$ Our results with the T. cordifolia leaf support the glycation inhibitory potential of T. cordifolia stem. Aqueous extract of $P$. marsupium bark has shown anti-cataract activity in alloxan diabetic rats. ${ }^{21}$

The antiglycation effects observed under in vivo conditions may have resulted partly due to the hypoglycaemic effects of those plant extracts. In our study, sugar concentration was similar in the incubation mixtures in presence and absence of the extract. Hence the antiglycation activities observed are independent of the possible hypoglycaemic effects of these extracts.

A good correlation has been shown to exist between free radical scavenging capacity and antioxidant activity of the plant extract and glycation inhibitory activity. ${ }^{22}$ Tannins and certain flavanoids are known to be potential free-radical scavengers. It is evident that a positive correlation exists between the total phenolic content of the plant extract and their glycation inhibitory potential. ${ }^{22}$ Some studies have shown free radical scavenging and antioxidant capacity in several plants used in our study. In vitro free radical scavenging and antioxidant activities of $C$. grandis leaf extract were observed which was suggested to be attributed to the presence of phenolic and flavanoid compounds in the leaf. ${ }^{23}$ Tannin fraction of Ficus racemosa possessed a significant antioxidant potential in vitro. ${ }^{24}$ Ethanol extract of $F$. racemosa bark exhibited concentration dependent hydroxyl radical and superoxide radical scavenging and inhibition of lipid peroxidation with an $\mathrm{IC}_{50}$ comparable with tested standard compounds. ${ }^{25} \mathrm{~A}$ significant antioxidant activity was found in alcoholic extract of $G$. sylvestre which was suggested to be partly due to the presence of phenolic compounds. ${ }^{26}$ Methanolic extract of $M$. paradisiaca inflorescence has showed effective antioxidant potential. ${ }^{18}$ In vitro antioxidant activities of of hydromethanolic extracts of C. Grandis leaves was shown. Ethanolic extracts of $P$. emblica had a strong antioxidant activity and high total polyphenol and tannin content. ${ }^{27}$ Oral administration of P. emblica extracts to streptozotocin-induced diabetic rats reduced the level of 5-hydroxymethylfurfural which is an indicator of oxidative stress. ${ }^{28}$ Strong antioxidant potential and a correlation between the antioxidant activity and total phenolic content were observed in $P$. debilis. ${ }^{29}$ Aqueous extract of $P$. marsupium stem bark showed high in vitro antioxidant activity in all assays used and also protected rat liver mitochondria against oxidative damage. ${ }^{30} P$. marsupium latex resin is known to contain about $75 \%$ of tannic acid which may have contributed to the strong antiglycation activity we have observed. Ethanolic extract of $S$. potatorum seeds showed normalization of in vivo antioxidant activity with a significant reduction of blood glucose level in streptozotocin-induced diabetic rats. ${ }^{31}$ The alterations of blood glucose level and antioxidant status in alloxan induced diabetes rats have been restored to normal levels by administration of T. cordifolia stem methanol extract, indicating the protective role of T. cordifolia. ${ }^{32}$ Even though previous studies demonstrated free radical scavenging and antioxidant capacities of some plant parts used, assessment of those activities in the methanol extracts of all ten plant parts used in our study is necessary to find out the correlation of those activities with the antiglycation activity observed.

\section{CONCLUSIONS}

We were able to demonstrate the antiglycation potential of some medicinal plants with known hypoglycemic effects, using a novel method developed by us recently. $P$. debilis whole plant, $P$. emblica fruit and $P$. marsupium latex showed a strong glycation inhibitory potential using a novel method established by us. F. racemosa stem bark showed the highest inhibition among the remaining seven plant extracts.

\section{ACKNOWLEDGEMENTS}

Financial assistance from National Science Foundation grant RG/2012/BS/01, Prof. R. Sivakanesan for revising the manuscript, Mr. A.M.P.S.T.M. Bandara and Ms. W. K. V. K. Premadasa for assistance with electrophoresis, Mr. G. Gunasekera for photography and Deputy Director, National Herbarium, Peradeniya for authenticating the plants.

\section{REFERENCES}

1. Odjakova M, Popova E, Sharif MA and Mironova R. Plant-derived agents with anti glycation Activity, Glycosylation, S. Petrescu (Ed.), 2012;ISBN: 978-953-51-0771-2, InTech, DOI: 10.5772/48186. Available from: http://www.intechopen.com/books/glycosylation/ plant-derived-agents-with-anti-glycation-activity

2. Goh SY and Cooper ME. The role of advanced glycation end products in progression and complications of diabetes. Journal of Clinical Endocrinology and Metabolism 2008; 93(4):1143-1152.

3. MuthennaP and ChandrasekharA. Ellagic acid, a new antiglycating agent: its inhibition of Nlunate epsilon-(carboxymethyl) lysine. Biochemical Journal 2012; 442(1):221-230.

4. Wautier JL and Schmidt AM. Protein glycation a firm link to endothelial cell dysfunction. Circulation research 2004; 95(3):233-238.

5. Ediriweera ERHSS and Ratnasooriya WD. A review on herbs used in treatment of diabetes mellitus by Sri Lankan ayurvedic and traditional physicians. Ayu 2009; 30 (4):373-391.

6. Ayatollahi SAM, Kobarfard F, Asgarpanah J and Choudhary MI. Antiglycation activity of Otostegia persica (Burm.) Boiss. Afr $\mathrm{J}$ Biotechnology 2010; 9(24):3645-3648.

7. Povichit N., Phrutivorapongkul A., Suttajit M., Chaiyasut C. and 
Leelapornpisid. P. Phenolic content and in vitro inhibitory effects on oxidation and protein glycation of some Thai medicinal plants. Pak. J. Pharm. Sci 2010; 23(4):403-408.

8. Ho SC, Chang PW, Tong HT and Yu PY. Inhibition of fluorescent advanced glycation end-products and $\mathrm{N}$-carboxymethyllysine formation by several floral herbal infusions. International Journal of Food Properties 2014; 17(3):617-628.

9. Wijetunge DCR and Perera HKI: A novel in vitro method to identify protein glycation inhibitors. Asian Journal of Medical Sciences 2014; 5(3):15-21.

10. Electrophoresis Technical Handbook: [online] 2010. Available from: URL: http://sinapseinc.com/files/Handbook-Eletroforese.pdf

11. Grover JK, Yadav S and Vats V. Medicinal plants of India with anti-diabetic potential. Journal of Ethnopharmacology 2002; 81(1):81-100.

12. Prabhakar PK and Doble M. A target based therapeutic approach towards diabetes mellitus using medicinal plants. Current Diabetes Reviews 2008; 4(4):291-308.

13. Khan V, Najmi AK, Akhtar M, Aqil M, Mujeeb $M$ and Pillai KK. A pharmacological appraisal of medicinal plants with antidiabetic potential. Journal of Pharmacy and Bioallied sciences 2012; 4(1):27-42.

14. Perera PRD, Sagarika Ekanayaka $S$ and Ranaweera KKDS. In Vitro antiglycation Activity of some medicinal plants used in diabetes mellitus. Med Aromat Plants 2013; 2(6):143-145.

15. Suryanarayana P, Saraswat J, Petrash JM and Reddy GB. Emblica officinalis and its enriched tannoids Check spelling delay streptozotocin induced diabetic cataract in rats. Mol Vis. 2007; 13:291-297.

16. Kaewnarin $K$, Niamsup $H$, Shank $L$ and Rakariyatham $N$. Antioxidant and antiglycation activities of some edible and medicinal plants. Chiang Mai J. Sci 2014; 41(1):105-116.

17. Bandara T, Rokeya B, Khan S, Ali L, Ekanayake S, Jansz ER et al. Effects of Gymnema lactiferum leaves on glycemic and lipidemic status in type 2 diabetic subjects. Bangladesh Journal of Pharmacology 2009; 4(2):92-95.

18. Nisha $\mathrm{P}$ and Mini $\mathrm{S}$. In vitro antioxidant and antiglycation properties of methanol extract and its different solvent fractions of Musa paradisiaca L. (cv Nendran) inflorescence. International Journal of Food Properties 2014; 17(2):399-409.

19. Patel MB and Mishra S. Isoquinoline alkaloids from Tinospora cordifolia inhibit rat lens aldose reductase. Phytotherapy Research 2012; 26(9):1342-1347.

20. Nadig PD, Revankar RR, Dethe SM, Narayanswamy SB and Aliyar MA. Effect of Tinospora cordifolia on experimental diabetic neuropathy. Indian Journal of Pharmacology 2012; 44(5):580-588.

21. Vats V, Yadav SP, Biswas NR and Grover JK. Anti-cataract activity of Pterocarpus marsupium bark and Trigonella foenum-graceum seeds extract in alloxan diabetic rats. J Ethnopharmacol. 2004; 93:289-294.

22. Dearlove RP, Greenspan P, Hartle DK, Swanson RB and Hargrove JL. Inhibition of protein glycation by extracts of culinary herbs and spices. J Med Food 2008; 11(2):275-281.

23. Umamaheswari $\mathrm{M}$ and Chatterjee TK. In vitro antioxidant activities of the fractions of Coccinia grandis L. leaf extract. African Journal of Traditional, Complementary and Alternative Medicines 2008; 5(1):61-73.

24. Sankaradoss N, Arun S, Naveen B., Sivanagamoorthi M and Velayudem R. Antioxidant [ $I n$ vitro] and analgesic activity [In vivo] of tannin fraction of stem bark of Ficus racemosa Linn. Research Journal of Pharmaceutical, Biological and Chemical Sciences 2012; 3(1):597-603.

25. Veerapur VP, Prabhakar KR, Thippeswamy BS, Bansal P, Srinivasan KK and Unnikrishnan MK. Antidiabetic effect of Ficus racemosa Linn. stem bark in high-fat diet and low-dose streptozotocin-induced type 2 diabetic rats: A mechanistic study. Food Chemistry 2012; 132(1):186-193.

26. Rachh PR, Patel SR, Hirpara HV, Rupareliya MT, Rachh AS, Bhargava NM et al. In vitro evaluation of antioxidant activity of Gymnema sylvestre r. br. leaf extract. Rom. J. Biol.-Plant Biol 2009; 54(2):141-148.

27. Kusirisin $W$, Srichairatanakool $S$, Lerttrakarnnon $P$, Lailerd N, Suttajit M, Jaikang C et al. Antioxidative activity, polyphenolic content and antiglycation effect of some Thai medicinal plants traditionally used in diabetic patients. Medicinal Chemistry 2009; 5(2):139-147.

28. Rao TP, Sakaguchi N, Juneja LR, Wada E and Yokozawa T. Amla (Emblica officinalis Gaertn.) extracts reduce oxidative stress in streptozotocin-induced diabetic rats. Journal of Medicinal Food 2005; 8(3):362-368.

29. Kumaran A. and Joel KR. In vitro antioxidant activities of methanol extracts of five Phyllanthus species from India. Food Science and Technology 2007; 40(2):344-352.

30. Mohammadi M, Khole S, Devasagayam TPA and Ghaskadbi SS. Pterocarpus marsupium extract reveals strong in vitro antioxidant activity. Drug discoveries and therapeutics 2009; 3(4):151-161.

31. Mishra SB, Verma A and Vijayakumar M. Preclinical valuation of anti-hyperglycemic and antioxidant action of Nirmali (Strychnos potatorum) seeds in streptozotocinnicotinamide-induced diabetic Wistar rats: A histopathological investigation. Biomarkers and Genomic Medicine 2013; 5(4):157-163.

32. Sivakumar $\mathrm{V}$ and Rajan MD. Antioxidant effect of Tinospora cordifolia extract in alloxan-induced diabetic rats. Indian journal of pharmaceutical sciences 2010; 72(6): 795-798. 